\title{
Arquivo e arte contemporânea: perspectivas da Ciência da Informação
}

\author{
Archive and contemporary art: perspectives of Information Science
}

\begin{abstract}
Bruno Cesar Rodrigues Doutorando pelo Programa de Pós-Graduação em Ciência da Informação da Escola de Comunicações e Artes da Universidade de São Paulo - ECA-USP

E-mail: brunocesar.rodrigues@gmail.com
\end{abstract}

ARANTES, Priscila. Re/escrituras da arte contemporânea: história, arquivo e mídia. Porto Alegre: Sulina, 2015.

Priscila Arantes é diretora do Paço das Artes desde 2007, além de curadora, pesquisadora e crítica no campo da estética contemporânea. Por meio de suas experiências tanto na pesquisa quanto na prática curatorial, redigiu o livro Re/escrituras da arte contemporânea: história, arquivo e mídia, o qual entrelaça discussões acerca do da curadoria e da condição da obra de arte contemporânea que ocupa o arquivo, ou é proveniente dele, contribuindo grandemente com os debates correlatos. Embora sua escritura parta de um conhecimento filosófico, perpassando as práticas curatoriais, percebemos as possibilidades de caminhos que também a Ciência da Informação pode percorrer. Em concordância com Simone Osthoff, que escreve no prefácio da obra, percebemos este livro como um subsídio acadêmico importante para pensarmos as questões que envolvem o arquivo e a documentação no campo das artes contemporâneas.

Arantes tem interesse pelo diálogo que a arte contemporânea promove junto ao arquivo por ter se deparado com a arte como um processo que exigia sua documentação, seu registro, também considerando sua efemeridade e desmaterialização. Assim, aproveitou-se de sua experiência no Paço das Artes, instituição que ela frisa não se tratar de um museu no sentido estrito do termo, mas que ela classifica mais como um arquivo de arte contemporânea, para tecer suas considerações acerca destes assuntos. Ela busca desenvolver suas discussões por meio de "Artistas que trabalham com material de arquivo, que criam arquivos fictícios, que problematizam a questão do arquivamento, artistas que desenvolvem projetos a partir de uma modalidade arquival [...]" (ARANTES, 2015, p. 19).

Sua obra se divide em duas partes, sendo a primeira um desenvolvimento do conceito que ela chama de "re/escritura da história como forma de entendimento da mesma não como 
representação mimética de um passado inerte, mas como dispositivo passível a novas e diferentes apresentações” (ARANTES, 2015, p. 19). Ela faz uso de pensadores conhecidos para sustentar suas considerações, tais como Vilém Flusser, Walter Benjamin, Henri Bergson, Aby Warburg e Georges Didi-Huberman. Já na segunda parte sua atenção se volta mais para as discussões que encontramos no campo da arte contemporânea e do uso pelos artistas com os materiais de arquivo com os quais eles têm trabalhado.

Na primeira parte de seu livro, Arantes (2015) inicia seu pensamento sobre a história partindo dos autores que trabalham com conceitos de ruínas, morte e fim. Exemplos a serem citados temos Hans Belting com seu livro O fim da história da arte no qual ele postula não o fim, de fato, da arte, mas, sim, da pretensão histórico-linear da arte. Para o autor, o modo como a narrativa vinha sendo desenvolvida tem seu encerramento em meados do século XX. No que concerne ao museu, Arantes (2015) cita Douglas Crimp e o livro Sobre as ruínas do museu. Neste o autor determina a morte deste tipo de instituição, ou melhor, “[...] se refere à ruína da ficção museológica de representar a arte como um sistema homogêneo, pretensamente universal, e a história da arte como sua classificação ideal "(ARANTES, 2015, p. 31).

Com as temáticas da história, Priscila Arantes (2015) entrelaça a questão da memória, discutida pela história, com a ideia apresentada por Paul Virillo de que vivemos numa sociedade do esquecimento, pois que esta é marcada pela velocidade e a interação em tempo real, o que dificulta a narrativa histórica. Assim, ela questiona de que modo podemos falar de história, de memória, de arquivo se o que vivemos hoje é a cultura do tempo real, do instantâneo? Para ela há um “[...] mar de 'ruínas" ” no qual “ talvez fosse interessante resgatar os 'cacos' da história, para construir alguns possíveis olhares em relação ao nosso tempo " (ARANTES, 2015, p. 32). Assim, para ela a ideia de re/escritura vem ao encontro da abertura de possibilidades para “"outras ' narrativas, 'outras' histórias, vozes e significados possíveis” (ARANTES, 2015, p. 33).

Em continuidade e finalizando a primeira parte, a autora parte para uma discussão da arqueologia das imagens técnicas, na qual ela aborda tanto a imagem fia quanto a imagem em movimento, perpassando as mídias e o armazenamento dos dados com vistas a estabelecer relacionamentos entre história e mídia na atualidade. Arantes $(2015$, p. 81) ressalta a importância de "não somente destacar as modificações na concepção de 'tradicional' da narrativa histórica, mas também os deslocamentos em relação à concepção 'tradicional' de arquivo". 
Na segunda parte do livro, Priscila Arantes (2015) adentra o contexto da obra de arte contemporânea, no qual percebemos que os documentos comprovam a existência da obra de arte; mesmo que tal existência tenha se dado por um prazo finito, durante sua exposição. Assim; os documentos configuram-se também como mediadores entre o passado e o presente, configurando-se como memórias que dão sobrevida às obras já realizadas e que, devido ao seu processo artístico, não existem mais. A efemeridade das obras de arte contemporânea vem tratar ressaltar a questão do esquecimento indicado acima, pois, mesmo que se tenha todos os registros, elas nunca estão completas. Algumas obras não estão completas nem mesmo durante a apresentação, a não ser com a participação dos públicos, indicando a inserção da subjetividade da participação como item essencial de composição da arte em exibição. Neste caso, há sempre algo que não será documentado, mas o que for será tido como memória. Então, Priscila Arantes (2015, p. 91-92) vem nos dizer que "O arquivo seria uma noção abstrata do conjunto de regras de um sistema discursivo de uma determinada época, e não a noção corrente cuja matéria resume-se aos escritos que documentam ou testemunham o passado, guardado e imóvel”.

A autora aborda as diversas perspectivas do arquivo na arte contemporânea perpassando-o enquanto dispositivo que auxilia a história da arte; o arquivo enquanto poética e dispositivo performativo, sempre tendo o Paço das artes como ponto de partida de suas reflexões. Podemos entender que, para ela, os registros, os documentos e os arquivos em si não são estáticos, mas também estéticos, o que significa que eles tanto podem conter como contêm materiais com finalidades estéticas e não apenas documentais, o que é possível observar a partir da experiência da autora e seus tetos publicados acerca do assunto; eles também abrangem documentos que, em determinadas circunstâncias, seja por contar certas informações, seja por seleção curatorial, podem mudar seu status para obra de arte. Um exemplo que se entrelaça com os sentidos da arte, ou arquivo artístico, que podemos citar é o de Paulo Bruscky. Cristina Freire (2006) apresenta-nos todo um apanhado desse arquivo que é um conjunto de memórias que se mescla à produção artística tornando-se ele próprio (conteúdo do arquivo) em obra de arte.

A desmaterialização das obras de arte, o processo de hibridização das linguagens artísticas, a incorporação da dimensão do tempo, além do processo de produção das obras de arte, são fatores que tornam o arquivo importante para as artes contemporâneas, segundo dizeres de Arantes (2015), o que, inclusive, trouxe questionamentos várioscom relação às práticas de arquivamento: “[...] os vestígios e os documentos residuais passam, em alguns casos, a fazer parte da operação intrínseca da própria obra” (ARANTES, 2015, p. 101). A autora procura ressaltar que, para ela, o arquivo é um processo vivo, cheio de lacunas e sintomático no qual há 
a contínua possibilidade de construir narrativas que possuem outras perspectivas de história e história da arte.

O arquivo é passível de ser considerado como mais um caminho exequível para se contar a história da arte, mas acreditamos que de uma forma um tanto quanto diferente daquela proposta pelos museus. Há semelhanças, ainda assim, entre as duas instituições, sendo elas a guarda, a preservação de acervos e a forte ligação com a memória, processando as informações contidas e disponibilizando-as à sociedade. Apesar da similitude, ainda vemos que há uma separação bem definida entre as áreas de guarda das instituições de arte, cada uma com sua metodologia, sem uma real junção dos fazeres e técnicas para uma melhor organização dos materiais de obras conceituais, desmaterializadas (LIPPARD, 2001), incorporais (CAUQUELIN, 2008), relacionais (BOURRIAUD, 2009). Nesse caso Arantes (2015) vem em defesa do arquivo como fonte de informação importante na concepção da arte contemporânea quando afirma que os registros documentais que os arquivos possuem têm sido cada vez mais insumo artístico: “[...] os dispositivos arquivais, como o vídeo e a fotografia, por exemplo, foram muitas vezes elementos de criação e produção de linguagem" (ARANTES, 20015, p. 115), assim, não se deve limitar uma obra de arte a seus documentos e registro, "mas [...] perceber que existe certa operação 'arquival' inerente à arte contemporânea em função do processo de desmaterialização artística, da introdução de novos meios no campo da arte e da incorporação da dimensão do tempo e do processo em seu fazer"' (ARANTES, 20015, p. 117, grifo da autora).

Com base nisso, Priscila Arantes (2015) advoga em favor do arquivo alegando que ele não deve ser entendido como "depósito de documentos", mas, sim, como um espaço que possibilita às obras ampliar suas perspectivas.

A obra de arte contemporânea é, com efeito, um arquivo em um sentido muito particular: um arquivo-obra aberto a inúmeros desdobramentos, leituras e 'múltiplas narrativas'. Artistas que trabalham com material de arquivo, artistas que criam arquivos fictícios, artistas que problematizam a questão do arquivamento, artistas que desenvolvem projetos a partir de uma modalidade arquival são algumas das propostas que encontramos no campo da arte contemporânea.

[...] O arquivo passa a ser, portanto, não somente tema ou matéria prima de muitas obras, mas operação intrínseca de muitas delas (ARANTES, 20015, p. 120, grifo da autora).

O que percebemos, então, é que o arquivo de museu se torna responsável tanto pela organização dos documentos da entidade quanto das obras que compõem seu acervo. Ele também tem a capacidade de narrar uma história permeando outro caminho diferente daquele 
muitas vezes hegemônico e cronológico da história da arte. Isso se dá devido às transformações ocorridas no cenário da produção artísticas, bem como da crise institucional pela qual

[...] se vê num impasse o que diz respeito à incorporação em seu acervo de propostas da arte contemporânea que, muitas vezes, colocam em xeque premissas válidas para as instituições tradicionais: em vez da permanência, a transitoriedade; em vez da autonomia, a contextualização; a autoria se esfacela frente às poéticas da apropriação e a unidade é colocada em xeque pela reprodutibilidade técnica (ARANTES, 2015, p. 168).

A expansão promovida pelas artes tem direcionado os profissionais para novas formas de realizarem os processos de documentação, catalogação e preservação das obras, alega a autora, o que promove os trabalhos a serem feitos cada vez mais em equipes, uma vez que apenas os conhecimentos museológicos e arquivísticos não serem suficientes para a realização das tarefas, afirma Arantes (2015). Isto é, ela defende a necessidade de profissionais e/ou equipes com conhecimentos multidisciplinares, pois precisam estar envolvidos em diversas frentes para execução de suas atividades.

Podemos concluir, a partir do que nos apresenta Priscila Arantes (2015) e de outras leituras, em contribuição com o campo da Ciência da Informação, que o arquivo é - ou passa a ser - o espaço no qual o pesquisador pode se sentir mais livre para decidir qual caminho quer percorrer, qual história pode ser contada, e não apenas aceitar aquela afixada pela seleção e disposta pela instituição em forma de exposição. No arquivo o pesquisador é quem estabelece o valor a partir dos documentos ali encontrados, criando sua própria narrativa. Para isso é preciso que o profissional da informação esteja preparado para trabalhar com as diversidades provenientes das produções das artes contemporâneas. As propostas arquivais desse domínio das artes

Trata-se não de imitar o real ou de representar algo, trata-se não de representar o passado ou o "mesmo"; trata-se de apresentar, de contar de outra forma, de se apropriar, reencenar, multiplicar o outro gerando e produzindo assim uma episteme diversa da representação: o da repetição diferente.

A “originalidade" desses trabalhos não pode ser outra que o da repetição diferente. A diferença, aqui, é fundamental, o dispositivo que possibilita novas e diferentes re/escrituras (ARANTES, 2015, p. 196, grifo da autora). 


\section{Referências}

ARANTES, P. Re/escrituras da arte contemporânea: história, arquivo e mídia. Porto Alegre: Sulina, 2015.

BOURRIAUD, N. Estética relacional. São Paulo: Martins Fontes, 2009.

CAUQUELIN, A. Frequentar os incorporais: contribuição a uma teoria da arte contemporânea. São Paulo: Martins, 2008.

FREIRE, C. Paulo Bruscky: arte, arquivo e utopia. São Paulo: [s.n.], 2006.

LIPPARD, L. Six years: the dematerialization of the art object from 1966 to $1972 \ldots$ New York: Praeger, 2001. 